\title{
Study of the interaction between poly(ethylene oxide) and phenol-formaldehyde resin
}

\author{
Karen R. Stack, Lawrence A. Dunn and Noel K. Roberts \\ Natural Resources Chemical Research Centre, Department of Chemistry, University of \\ Tasmania, Hobart, Tasmania 7001, Australia
}

(Received 19 February 1991; accepted 20 June 1991)

\begin{abstract}
Interactions between poly(ethylene oxide) and phenol-formaldehyde resin play important roles in the mechanism by which the two polymers improve fibre retention in the papermaking process. These were investigated at the concentration level and shear conditions found in this process. The results indicate that the complex formed varies with $\mathrm{pH}$ and ionic strength over a very narrow range of conditions, and that the self association of the resin plays an important part in the quantity of resin in the complex. Because the amount of resin interacting with the polyethylene oxide appears to be related to the molecular weight, and hence chain length, of the two polymers, cooperative binding of the polymers seems to be involved. A minimum size of the network was found to be necessary for the polymers to improve fibre retention.
\end{abstract}

\section{INTRODUCTION}

Poly(ethylene oxide) (PEO) and phenol-formaldehyde resin (PFR) have been found to constitute a very effective dual retention aid system in some newsprint mills [1-5]. Quite small concentrations of the polymers [1] have been found to improve fibre retention significantly. However, there are some mills in which it has not been effective [2,4]. Specific reasons for this have not been identified, though it has been found that the dual polymer system is sensitive to pulp composition and process water contamination $[2,3,5]$. Degradation of PEO due to shear and polymer aging have also been suspected of causing poor response of the retention aid system [4]. Therefore, an understanding of the interaction between PFR, PEO and pulp fibres, and the effect of variables in the pulping process are of great interest.

Lindstrom and Glad-Nordmark [6] proposed that improved retention and flocculation occur via a mechanical enmeshment mechanism in a transient network formed by the complexation of the two polymers. 
They showed that a network structure was formed because they were able to fractionate mixtures of latex particles according to size with the PFR-PEO complex. No detailed study of the interaction between the polymers has been conducted, though complex formation between $\mathrm{PEO}$ and phenolic compounds is well known [8-12]. At the low concentrations of the polymers used in the industrial situation, the polymer network is formed within seconds of mixing the polymers [7]. and is believed to be unstable.

A preliminary investigation of the interaction between the polymers and fibres indicated that the nature of the PFR-PEO complex varies with $\mathrm{pH}$ and polymer ratio [13]. It is known that the retention aid performance of $\mathrm{PEO}$ deteriorates [3] when its molecular weight is less than $3-4 \cdot 10^{6}$. Little has been reported about this effect in the presence of PFR, though it has been suggested that the molecular weight of PEO is not as critical as when PEO is used alone [14]. Resin type is known to affect the retention aid performance, though no detailed study has been reported.

This paper presents the results of a study of the interaction between the polymers at the concentration levels and shear conditions of the papermaking process. The dynamic drainage jar has been used to simulate the shear conditions of the paper machine, and the experimental conditions used in a typical fibre retention measurement have been chosen to investigate the interaction [13]. An investigation of the effects of stirrer speed and mixing time on the interaction between the polymers was conducted to determine the sensitivity to shear of the complex formed. Effects of $\mathrm{pH}$, ionic strength and electrolyte type were also studied to gain a better understanding of the effects of process changes on the interaction. The influence of the molecular weight of the two polymers has been investigated to see whether a critical molecular weight is needed to form a stable complex and thus influence the fibre retention of the polymers.

\section{EXPERIMENTAL}

\section{Materials}

A sample of PFR (Resinox IL 1510, Chemplex Australia) used as part of their dual retention aid system was supplied by Australian Newsprint Mills Ltd. (ANM), Albury. The neat resin was dialysed against distilled water for 4 days in dialysis tubing which had a molecular weight cut-off of 1000 . This was to remove impurities and excess $\mathrm{NaOH}$. High-performance liquid chromatography (HPLC) of the dialysed resin indicated that some of the low molecular weight components of the 
resin were also removed. However, retention performance of the resin was found to be unaffected by dialysis. The $\mathrm{p} K_{\mathrm{a}}$ for the resin was determined by potentiometric titration and found to be 9.6. Several experimental resins were also obtained from ICI Australia and Chemplex Australia and were used as received.

A sample of high molecular weight PEO used by ANM at Albury (supplied by Union Carbide) was obtained, and a $0.1 \%$ solution was prepared by slow addition of the powder to continuously stirred water. The solution was stirred for $90 \mathrm{~min}$. Samples from Union Carbide, Aldrich and Toyo Soda of PEO standards with molecular weight ranging from $8.6 \cdot 10^{5}-5 \cdot 10^{6}$ were also prepared.

Pulp samples were prepared using thermomechanical pulp produced from Pinus radiata. Fines content of the pulp was $65-70 \%$ and pulp consistency was $0.5 \%$.

\section{Experimental procedure}

\section{Complex formation experiments}

A dynamic drainage jar was used to mix the polymers. Distilled water $(400 \mathrm{ml})$ was added to the jar and the stirrer speed was adjusted as required. For most experiments a stirrer speed of $1100 \mathrm{rev} \mathrm{min}{ }^{-1}$ was used. PFR was added to the stirred solution via a syringe and allowed to stir for $10 \mathrm{~s}$ prior to the addition of the PEO. The solution was stirred for a further $20 \mathrm{~s}$, unless otherwise stated, after which the drainage clamp was removed and the suspension allowed to drain through a $76 \mu \mathrm{m}$ screen plate. The first $25 \mathrm{ml}$ of liquid drained was discarded and the next 20-30 ml collected.

The amount and composition of the complex formed when the two polymers were mixed was calculated by analysing the filtrate from the drainage jar and subtracting the amount of polymer present from that in the original mixture. PFR concentration in the filtrate was determined by measuring the absorbance of the peak at $285 \mathrm{~nm}$ in the ultraviolet (UV) spectrum. The $\mathrm{pH}$ of the solution was adjusted to 12 with $\mathrm{NaOH}$ prior to the UV absorbance measurement in order to dissolve any colloidal PFR. Colloidal PFR was found to pass through the screen in the drainage jar. PEO concentration was measured using tannic acid reagent [15] and measuring the transmission of the samples at $450,500,550$ and $600 \mathrm{~nm}$. Most experiments were carried out at two levels of polymer addition. The lower level of $10 \mathrm{ppm}$ PFR and $1 \mathrm{ppm}$ PEO corresponds to the level used in the industrial situation [1]. Determination of the concentration of the polymers at this level is not very accurate, as the experimental error in the measurement is $0.5 \mathrm{ppm}$ for PEO and $1 \mathrm{ppm}$ for PFR, using the methods described. Measurements 
were also made at a higher polymer concentration (25 ppm PFR and $2.5 \mathrm{ppm}$ PEO) to ensure that the data obtained were reliable and reproducible. Comparisons of the results at the two levels of polymer addition are made to ensure that the observations can be applied to the industrial situation.

The conductivity and $\mathrm{pH}$ of solutions were measured using a Jenway PWA2 water analyser and a TPS LC80 pH-millivolt meter.

\section{Retention performance experiments}

The dynamic drainage jar was used to measure fibre retention of pulp at various polymer additions. $500 \mathrm{ml}$ of pulp were added to the drainage jar which was fitted with a vane jar and machine fabric. A stirrer speed of $1100 \mathrm{rev} \mathrm{min}^{-1}$ and polymer contact times of $30 \mathrm{~s}$ for PFR and 20 s for. PEO were used.

\section{Molecular weight determination}

The apparent molecular weights of the resins were measured using gel permeation chromatography. A Varian 5020 LC with Varian 9060 polychrom detector was used, fitted with an Ultrapac Column TSK G2000HXL $(7.8 \mathrm{~mm} \times 300 \mathrm{~mm}, 5 \mu \mathrm{m}$ particle size). Tetrahydrofuran (THF) was used as the solvent. The resins were found to be insoluble in THF so $4-5$ drops of trichloroacetic acid (10\% solution in THF) [16] were added to $2-3 \mathrm{ml}$ of neat resin ( $40 \%$ solids) and the volume made up to $25 \mathrm{ml}$ with THF. Polystyrene was used to calibrate the column over the molecular weight range of 400-35 000 .

\section{RESULTS}

\section{Effect of shear}

Figure 1 shows the effect of stirrer speed on the amount of PFR interacting with PEO at two levels of polymer addition in the absence and presence of electrolyte. The mixing time of the polymers in the drainage jar was maintained at $10 \mathrm{~s}$ for the PFR then a further $20 \mathrm{~s}$

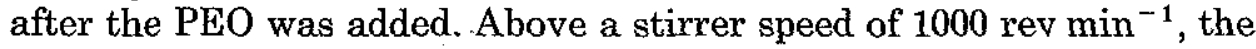
amount of PFR interacting with $\mathrm{PEO}$ remains constant. No degradation of the PFR-PEO complex is evident at the high shear conditions imposed by the drainage jar.

The effect of mixing time of the polymers in the drainage jar on the interaction was also investigated (Fig. 2), at a constant stirrer speed of $1100 \mathrm{rev} \mathrm{min}^{-1}$. After $15 \mathrm{~s}$ mixing time of the two polymers, the amount of PFR in the complex appears to reach a constant value. Even after 5 min at these shear conditions, the PFR-PEO complex appears 


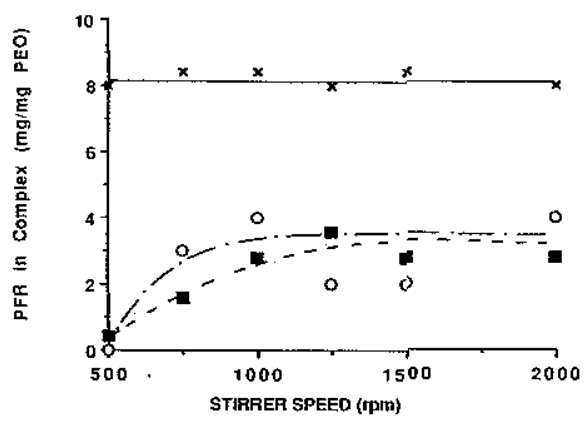

Fig. 1. Effect of stirrer speed on the amount of PFR interacting with PEO. (O) $10 \mathrm{ppm}$ PFR, $1 \mathrm{ppm}$ PEO, $0.01 \mathrm{M} \mathrm{KNO}_{3}$; (ם) $25 \mathrm{ppm}$ PFR, $2.5 \mathrm{ppm}$ PEO, no electrolyte; ( $\mathrm{x}$ ) $25 \mathrm{ppm}$ PFR, $2.5 \mathrm{ppm} \mathrm{PEO}, 0.01 \mathrm{M} \mathrm{KNO}_{3}$.

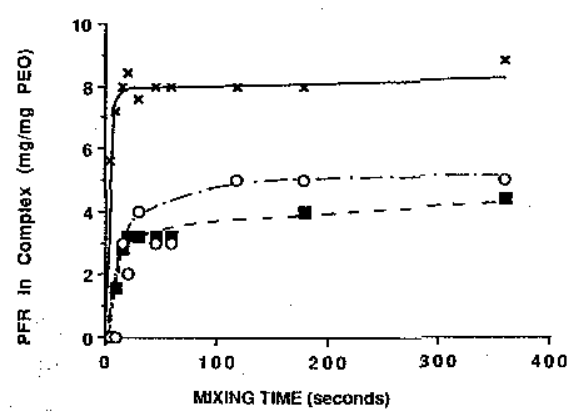

Fig. 2. Effect of mixing time in the Drainage Jar on the amount of PFR interacting with PEO. (O) $10 \mathrm{ppm}$ PFR, $1 \mathrm{ppm}$ PEO, $0.01 \mathrm{MKNO}_{3}$; ( $) 25 \mathrm{ppm}$ PFR, $2.5 \mathrm{ppm}$ PEO, no electrolyte; ( $~ 25 \mathrm{ppm}$ PFR, $2.5 \mathrm{ppm}$ PEO, $0.01 \mathrm{M} \mathrm{KNO}_{3}$.

stable. The ratio of PFR:PEO in the complex, on a mass: mass basis, reaches an approximate value of $3-4$ both at $25 \mathrm{ppm}$ PFR/2.5 ppm PEO addition, in the absence of electrolyte, and at the lower polymer concentration of $10 \mathrm{ppm}$ PFR/ $1 \mathrm{ppm}$ PEO, in the presence of electrolyte. At the higher polymer addition; in the presence of electrolyte, the ratio of PFR: PEO in the complex is 8 .

\section{Effect of $p H$}

Figure 3 depicts the effect of $\mathrm{pH}$ on the interaction between PFR and $\mathrm{PEO}$, in the absence and presence of added electrolyte, as a function of the amount of PFR added. Solutions containing 0-50 ppm PFR were mixed in the drainage jar. To each solution $2.5 \mathrm{ppm}$ of PEO was added. $\mathrm{KNO}_{3}$ was added to maintain the ionic strength at $0.01 M$ in the solutions containing electrolyte. Under neutral and basic conditions (pH 6.5 and 9.5 respectively) the amount of $\mathrm{PFR}$ reacting with $\mathrm{PEO}$ 


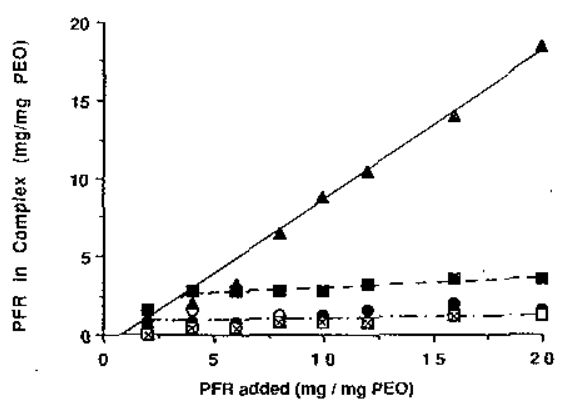

Fig. 3. Effect of $\mathrm{pH}$ on the amount of PFR interacting with $\mathrm{PEO}$ as a function of PFR

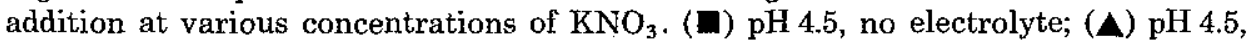
$0.01 \mathrm{MNO}_{3}$; (O) $\mathrm{pH} 6.5$, no electrolyte; (O) $\mathrm{pH} 6.5,0.01 M \mathrm{KNO}_{3} ;(\times) \mathrm{pH} 9.5$, no electrolyte; ( $\square$ ) pH 9.5, 0.01 $\mathrm{M} \mathrm{KNO}_{3}$.

was found to be constant ( $1 \mathrm{mg}$ per mg PEO added) and the amount of PFR in the complex was not influenced by the addition of electrolyte. Under acidic conditions ( $\mathrm{pH} 4.5$ ) and in the absence of electrolyte, the amount of PFR interacting with PEO appears to plateau at $3 \mathrm{mg}$ per mg PEO added. In the presence of $\mathrm{KNO}_{3}$, the amount of PFR in the complex continues to increase linearly.

In Fig. 4, the effect of $\mathrm{pH}$ on the amount of PFR interacting with PEO is presented at two levels of PFR and PEO addition, both in the absence and presence of $0.01 M \mathrm{KNO}_{3}$. The results indicate that the amount of $\mathrm{PFR}$ interacting varies with $\mathrm{pH}$. At low $\mathrm{pH}$, most of the PFR interacts with the PEO, but between $\mathrm{pH} 4-6$ the amount of PFR interacting decreases. Above this critical $\mathrm{pH}$ range, the amount of PFR interacting remains constant. The critical $\mathrm{pH}$ range appears to be dependent on ionic strength. In the absence of added electrolyte, the critical $\mathrm{pH}$ range is $4.5-5.5$ but in the presence of $0.01 M \mathrm{KNO}_{3}$, it is

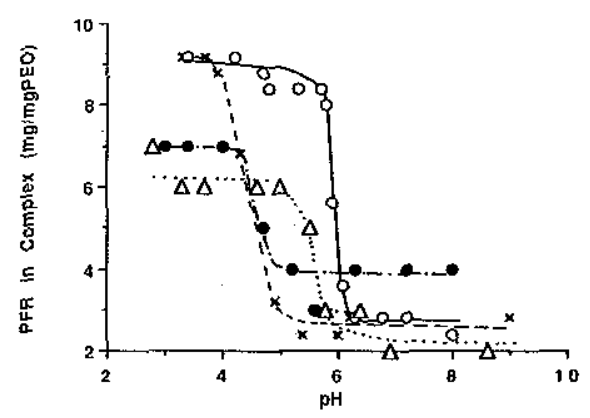

Fig. 4. Effect of $\mathrm{pH}$ on the amount of PFR interacting with PEO. (O) $25 \mathrm{ppm}$ PFR, $2.5 \mathrm{ppm}$ PEO, $0.01 \mathrm{M} \mathrm{KNO}_{3} ;(\times) 25 \mathrm{ppm}$ PFR, $2.5 \mathrm{ppm}$ PEO, no electrolyte; $(\triangle) 10 \mathrm{ppm}$ PFR, 1 ppm PEO, $0.01 \mathrm{M} \mathrm{KNO}_{3}$; (○) $10 \mathrm{ppm}$ PFR, 1 ppm PEO, no electrolyte. 
5.5-6.2. These ranges both appear to be independent of the total mass of polymer added.

Effect of ionic strength

Ionic strength effects on the interaction between the polymers were investigated at $\mathrm{pH} 5$ and 7 and a polymer addition of $25 \mathrm{ppm} \mathrm{PFR}$ and $2.5 \mathrm{ppm}$ PEO. $\mathrm{KNO}_{3}$ was used as the added electrolyte. The results presented in Fig. 5 show a sharp increase in the amount of PFR interacting with $\mathrm{PEO}$ at an ionic strength of $0.001-0.005 M$ at $\mathrm{pH} 5$. As the $\mathrm{pH}$ is increased to 7, the critical ionic strength at which the amount of PFR in the complex increases shifts to $>0.0075 \mathrm{M}$.

Effects of electrolyte type

A series of electrolytes were added to the solutions to determine if electrolyte type was influencing the degree of interaction between the polymers. The results at two levels of polymer concentration $(32 \mathrm{ppm}$ PFR : $2.5 \mathrm{ppm}$ PEO and $10 \mathrm{ppm}$ PFR: $1 \mathrm{ppm}$ PEO respectively) both show that electrolyte type does not appear to influence either the degree of interaction or the amount of PFR in the complex.

\section{Effect of PEO molecular weight}

In Fig. 6 the effect of PEO molecular weight on the interaction between PFR and PEO is presented. Here, the PEO concentration was maintained at $2.5 \mathrm{ppm}$ in $400 \mathrm{ml}$ of water and the $\mathrm{pH}$ was adjusted to 5 with $\mathrm{HCl}$. The amount of PFR interacting decreases as the molecular weight of the PEO decreases.

Figure 7 shows the effect of the PEO molecular weight on the reten-

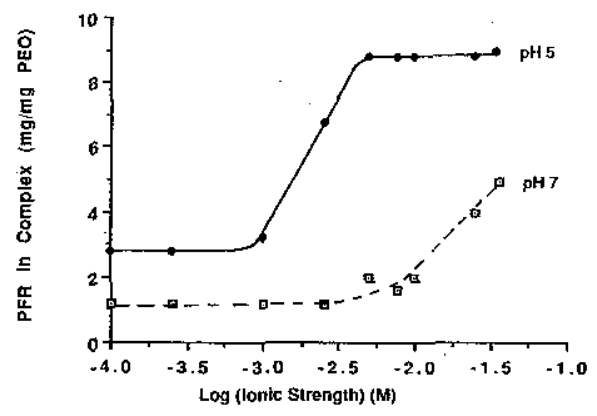

Fig. 5. Effect of ionic strength and $\mathrm{pH}$ on the amount of PFR interacting with PEO at constant polymer concentration (25 ppm PFR, $2.5 \mathrm{ppm} \mathrm{PEO}$ ). 


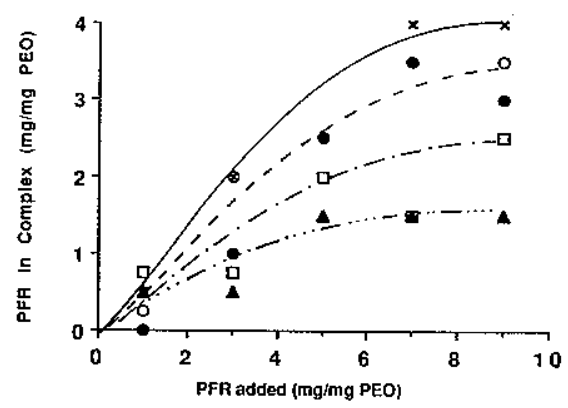

Fig. 6. Effect of PEO molecular weight on the amount of PFR interacting with PEO as a function of PFR addition. (X) 5 million; (8) 4 million; (D) 2 million; (A) 860000.

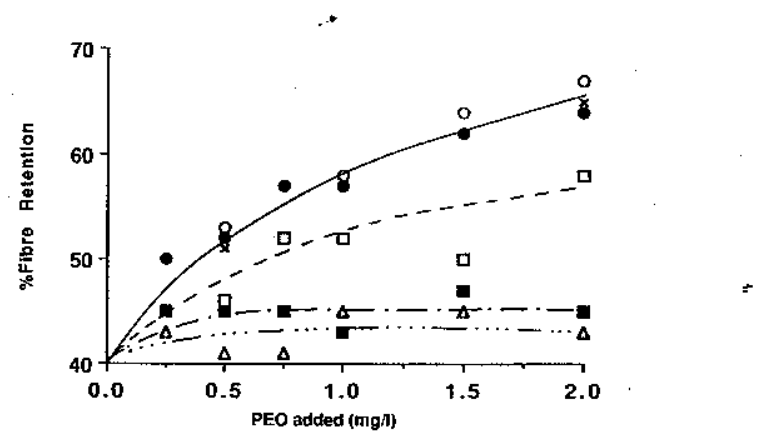

Fig. 7. Effect of PEO molecular weight on the fibre retention performance of the PEO/PFR retention aid system (PFR:PEO ratio, 6). ( $\times$ ) 5 million; (8) 4 million;

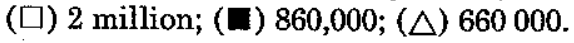

tion aid performance of the PFR-PEO combination. The PEO molecular weight was varied from $8.6 \cdot 10^{5}-5 \cdot 10^{6}$, with two samples of $4 \cdot 10^{6}$ being evaluated from different suppliers. The polymer concentration was varied from $1.5-12 \mathrm{mg} \mathrm{l}^{-1} \mathrm{PFR}$ and $0.25-2 \mathrm{mg} \mathrm{l}^{-1} \mathrm{PEO}$ and the ratio of $\mathrm{PFR}$ to $\mathrm{PEO}$ was maintained at 6 . The ratio chosen was that used in the industrial situation [1]. As the molecular weight of the PEO decreased from $5 \cdot 10^{6}$ to $2 \cdot 10^{6}$ the retention performance of the polymers was found to decrease. Very little retention improvement was found using PEO with a molecular weight of $8.6 \cdot 10^{5}$ or less.

\section{Effect of PFR molecular weight}

Figure 8 shows the effect of the addition of various resins to $2.5 \mathrm{ppm}$ $\mathrm{PEO}$ in $400 \mathrm{ml}$ of distilled water. $\mathrm{HCl}$ was used to adjust the $\mathrm{pH}$ to 5 . Five resins of the resole type were evaluated; their apparent molecular weights, $M_{\mathrm{w}}$, were found to be 450 (Resin A), 550 (Resin B), 3000 (Resin C) and 13000 (Resin E). Resin D was insoluble in THF and so 


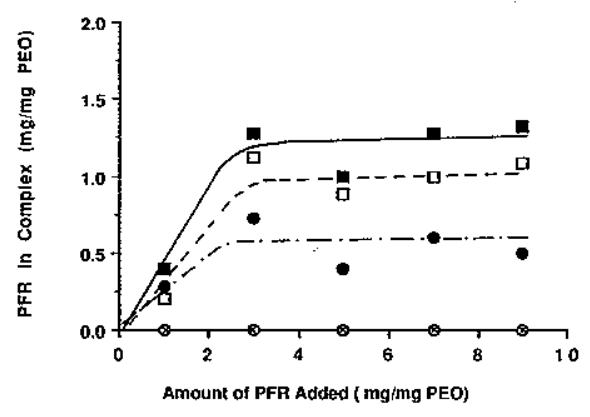

Fig. 8. Effect of PFR molecular weight on the amount of PFR interacting with PEO as a function of PFR addition. (O) Resin A; (x) Resin B; (O) Resin C; ( $\square$ ) Resin D; ( Resin E.

its molecular weight could not be measured. No interaction was observed when PEO was added to the two low molecular weight resins (Resin A and Resin B), while the resin with the highest molecular weight appeared to interact most with the PEO. The interaction of PEO with Resin D was more than that with Resin $\mathrm{C}$ but less than with Resin E, suggesting that its molecular weight was somewhere between 3000 and 13000 .

The various resins were also evaluated with $\mathrm{PEO}$ as retention aids. Figure 9 shows the retention improvement achieved by the addition of each resin and PEO to TMP pulp. Very little retention improvement occurred with Resins A and B while the higher molecular weight resins (Resins C-E) improved the fibre retention significantly. Resin E with the highest molecular weight gave the best retention performance.

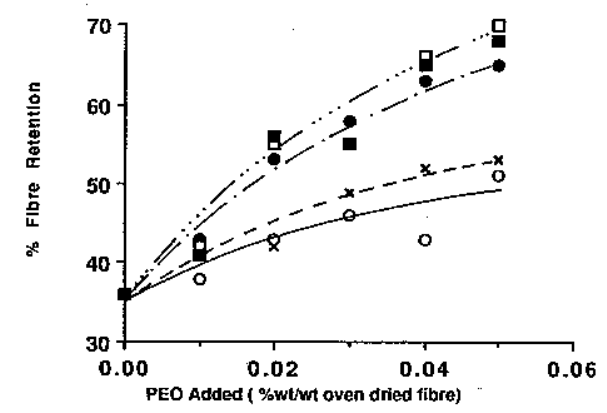

Fig. 9. Effect of PFR resin on the fibre retention performance of the PEO/PFR retention

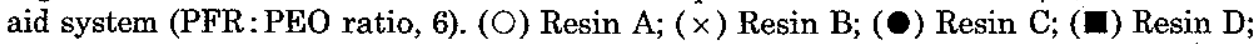
(口) Resin E. 


\section{DISCUSSION}

When PFR and PEO are mixed, a complex readily forms which separates from the solution. It is generally accepted that the complex is formed via hydrogen bonding between the ether groups of the PEO and the phenolic groups of the PFR [6,8]. PEO has associated with it a highly structured water layer $[17,18]$. PFR competes with this water layer and displaces it because it has a greater tendency for hydrogen bonding than the water molecules. This reduces the water solubility of the complex as the hydroxyl and ether groups are no longer available to associate with the water molecules.

Experimental results presented here indicate that the quantity of PFR interacting with $\mathrm{PEO}$ is dependent on both the $\mathrm{pH}$ and ionic strength of the solution. In acidic and high ionic strength solutions, the amount of PFR complexing with PEO is much greater than in neutral-alkaline and low ionic strength solutions. As shown in Figs 4 and 5 , the quantity of PFR in the complex varies over a very narrow range of $\mathrm{pH}$ and ionic strength. It appears that this critical region corresponds to the $\mathrm{pH} /$ ionic strength region in which PFR precipitates (Fig. 10). This suggests that the solubility of PFR influences the amount of PFR interacting with PEO. At high ionic strength, "salting out" of PFR occurs. This could be due to a change in the dielectric constant of the solution, as this is one factor that alters the solubility of PFR. Decreasing the $\mathrm{pH}$ of the solution also results in precipitation of PFR, as protonation of the PFR enhances its ability to form intramolecular hydrogen bonds [19] and so decreases its water solubility. Interaction between PEO and precipitated PFR which has self-associated via intermolecular hydrogen bonding results in a greater amount of PFR in the PFR-PEO complex at low $\mathrm{pH}$ and high ionic strength.

Under basic conditions and/or low ionic strength, the complex is a gel. However, at high ionic strength and low $\mathrm{pH}$, the complex is a

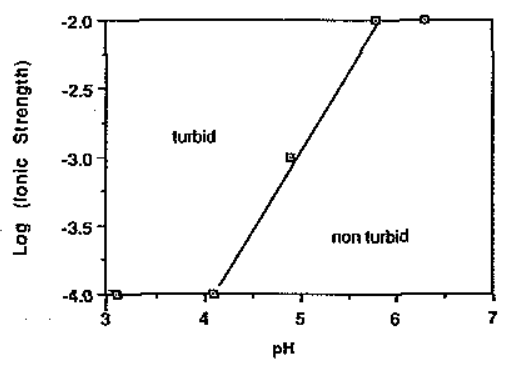

Fig. 10. Effect of $\mathrm{pH}$ and ionic strength on the solubility of PFR. 
precipitate. This change in appearance occurs over a very small region and can be attributed to the change in the solubility of the PFR.

These results have important implications in the application of the two polymers as retention aids since the critical $\mathrm{pH}$ and ionic strength region is in the operating region of most paper mills. Hence any small change to the $\mathrm{pH}$ and ionic strength of the pulp and process water may result in a change in the structure and nature of the PFR-PEO complex and hence affect the fibre retention.

Complex formation at any given $\mathrm{pH}$ and ionic strength appears to be independent of the shear conditions in the drainage jar after a short period of time. At the lower polymer addition used in the industrial situation (10 ppm PFR, $1 \mathrm{ppm}$ PEO), the complex does not appear to stabilise until after. $15 \mathrm{~s}$ of mixing. It is likely that the complex formed after this time period will undergo some breakdown before stabilising. Lindstrom [6] noted an apparent increase in viscosity of the solution after a few seconds. This is as a result of the initial formation of the networks which are possibly large, voluminous structures with a low PFR : PEO ratio in the network. It is at this stage in the formation of the networks that the fines are trapped [6]. With the partial breakdown of the network structure, the complex formed becomes more compact and the ratio of PFR:PEO in the complex increases, stabilising the structure. Figure 4 confirms that an increase in the PFR: PEO ratio in the complex occurs within the first $15 \mathrm{~s}$ of mixing at the lower polymer concentration.

PEO molecular weight was found to influence the amount of PFR interacting to form the complex. A stable complex was formed even with PEO of molecular weight as low as $8.6 \cdot 10^{5}$ though little fibre retention improvement occurred. It is indicated in Fig. 6 that the amount of PFR interacting appears to increase with molecular weight and hence with the chain length of the PEO. A dependence on the molecular weight of the resin is also apparent in Fig. 8 and the results suggest that a minimum molecular weight of the PFR is needed before a stable complex will form. This suggests that cooperative binding [20] is occurring in the formation of the complex. With the cooperative binding phenomena, a critical chain length (i.e. molecular weight) is needed above which a stable complex is formed. Binding between a site on PEO and a site on PFR is affected by adjoining sites which help to stabilize the complex.

Though a complex was formed when PEO with molecular weight $8.6 \cdot 10^{5}$ was used, no improvement in fibre retention occurred. This suggests that a minimum size of the complex is needed for fibre retention improvement.

The PEO-PFR interaction appears to be similar to the complexation 
between polyphenols and proteins [11,21-22]. This binding has been found to be strongly influenced by the molecular size of the polyphenol, its conformational flexibility and the water solubility of the polyphenol. It has been reported [22] that the ability of PEO to bind and to complex polyphenols and simple phenols shows a marked structural specificity. It was proposed that the bridging of PEO to molecules such as $1,3-$ dihydroxybenzene occurs because the separation between the $O(1)$ and $\mathrm{O}(3)$ ether groups in $\mathrm{PEO}$, when it adopts a helical structure [23], is similar to the distance between the dihydroxyphenolic groups $(\approx 5 \AA)$. Mathematical computation of the interatomic distances and charges on two simple model compounds for PFR and PEO were performed using the computer modelling program, PC Model (Version IV). The program predicted the distance between the alternate oxygens of the PEO model and the hydroxyl protons of the PFR model to be $7 \AA$. A zig-zag configuration for the $\mathrm{PEO}$ model was predicted. In the real situation the PEO molecule is much longer and the literature indicates that its preferred conformation is somewhat more compact than the zig-zag configuration. It is possible that the conformation of the PEO molecule could change to bind to a particular molecule and this could be one reason why PEO interacts with so many different compounds. In reality the PFR molecule would be a much larger and bulkier molecule than the model used in the computer simulation. It would contain more phenolic rings which would affect the orientation of the hydroxyls. Figure 11 illustrates how the PFR and PEO molecules may fit together.

An investigation into the effect of the chemical structure and size of the PFR on the interaction with $\mathrm{PEO}$ and the fibre retention performance with $\mathrm{PEO}$ is currently under way.

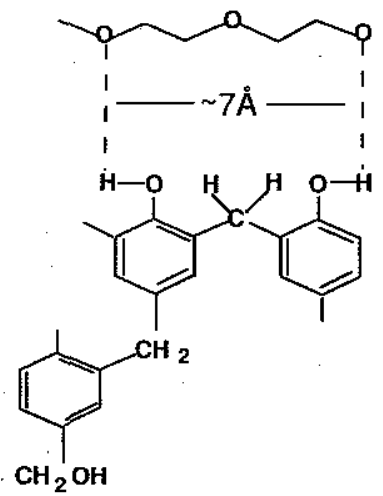

Fig. 11. Schematic diagram of the PEO molecule fitting to a polyphenol molecule in PFR. 


\section{CONCLUSIONS}

Complex formation between poly(ethylene oxide) (PEO) and phenolformaldehyde resin (PFR) is influenced by several factors including the water solubility of the PFR and the molecular size of the two compounds. Both the appearance of the complex and the quantity of PFR binding with $\mathrm{PEO}$ vary over a narrow range of $\mathrm{pH}$ and ionic strength. This has implications for its application as a retention aid, as the critical $\mathrm{pH}$ and ionic strength region are within the operating range of most paper mills. Under the shear conditions of the dynamic drainage jar, the structure of the complex appears to change. Initially, the complex is large and voluminous with a low PFR:PEO ratio. During the first $15 \mathrm{~s}$ of mixing, the structure breaks down to a more compact one with a higher PFR:PEO ratio in the complex. The more open initial structure is important in the retention mechanism. A minimum mesh size of the complex also exists before fibre retention improvement occurs, the size of which is governed by the PEO chain length. The type of PFR and possibly its molecular weight are also important in complex formation and retention improvement. Interaction between PFR and PEO appears to occur because the alternate oxygens on the PEO chain are the same distance apart as the hydroxyl protons on the PFR, thus allowing the molecules to fit together via intermolecular hydrogen bonding.

\section{ACKNOWLEDGEMENTS}

The authors gratefully acknowledge the generous financial support provided for this work by Australian Newsprint Mills Ltd. We also thank Chemplex Australia and ICI Australia for supplying samples of PFR, ANM Albury for supplying pulp and PEO samples, and ANM Research for the use of their facilities for gel permeation chromatography analysis.

\section{REFERENCES}

1 A. Barnes, R. Coghill and D. Thurley, Appita, 42(5) (1989) 373-375.

2 L. Rahman and C.H. Tay, Tappi, 69(4) (1986) 100-105.

3 C.H. Tay, Tappi, 63(6) (1980) 63-66.

4 R.H. Pelton, C.H. Tay and L.H. Allen, J. Pulp Paper Sci., 10(1) (1984) 5.

5 S. Shastri, Proc. 1983 Tappi Papermakers Conf., Portland, 25-27 April, 1983, TAPPI Press, Atlanta, 1983, pp. 205-210.

6 T. Lindstrom and G. Glad-Nordmark, J. Colloid Interface Sci., 97(1) (1982) 62-67.

7 L. Wagberg and T. Lindstrom, Colloids Surfaces, 27 (1987) $29-42$.

8 G. Fuch and H. Rupprecht, Colloids Surfaces, 6 (1983) 175-187. 
9 T. Lindstrom, Sep. Sci. Technol., 14(7) (1979) 601-610.

10 K.L. Smith, U.S. Patent 3,355,400, 1967.

11 W.T. Jones and J.L. Mangan, J. Sci. Food Agric., 28 (1977) 126-136.

12 G.G. Hammes and P.B. Roberts, J. Am. Chem. Soc., 90(7) (1968) 119.

13 K.R. Stack, L.A. Dunn and N.K. Roberts, Appita, 43(2) (1990) 125-129.

14 C.H. Tay and T.A. Cauley, Proc. 1982 Tappi Papermakers Conf., 5-8 April, 1982, TAPPI Press, Atlanta, 1982, pp. 205-210.

15 Y.A. Attia and J. Rubio, Br. Polym. J., 7 (1975) 135.

16 D.R. Bain and R.A. Wagner, Polymer, 25 (1984) 403-404.

17 R. Kjellander and E. Florin, J. Chem. Soc., Faraday Trans. 1., 77 (1981) 2053-2077.

18 K.J. Lui and J.L. Parsons, Macromolecules, 2(5) (1969) 529-533.

19 T. Cairns and G. Eglington, J. Chem. Soc., (1965) 5906.

20 E. Tsuchida and K. Abe, Adv. Polym. Sci., 45 (1982) 1-119.

21 C.M. Spencer, Y. Cai, R. Martin, S.H. Gaffney, P.N. Goulding, D. Magnolato, T.H. Lilley and H.:Haslem, Phytochem., 27(8) (1988) 2397-2409.

22 J.P. McManus, K.G. Davis, J.E. Beart, S.H. Gaffrey, T.H. Lilley and E. Haslem, J. Chem. Soc., Perkin Trans. 2, (1985) 1429-1443.

23 T. Yoshimura, H. Tadokoro and S. Marahashi, J. Chem. Phys., 41(9) (1964) 29022911. 